\title{
Mobility control ability and stability investigation of nitrogen foam under high temperature and high salinity condition
}

\author{
Bing Wang ${ }^{1} \cdot \operatorname{Lin} \operatorname{Sun}^{2} \cdot$ Mengyang $\mathrm{Shi}^{1} \cdot \operatorname{Tao}^{\operatorname{Tan}^{3}}$
}

Received: 13 November 2016/Accepted: 17 June 2017/Published online: 7 July 2017

(c) The Author(s) 2017. This article is an open access publication

\begin{abstract}
The mobility disparity between oil and water accounted for the poor water swept efficiency. Previous research has testified that nitrogen foam can increase sweep area and control water and gas mobility. However, the former studies have largely covered the mobility control ability performance in some conventional reservoir rather than that under high temperature and high salinity. This paper presents the results of a laboratory study of nitrogen foam at the experimental condition $\left(113^{\circ} \mathrm{C}\right.$ and $21.28 \times 10^{4} \mathrm{mg} / \mathrm{L}$ ) on its mobility control ability investigation, including different gas-to-liquid ratio, injection rate and core permeability; additionally, a novel method on studying the stability of mobility control ability of foam was utilized. Nitrogen foam injection was conducted in core holder to investigate the shape discrepancy of each resistance factor and residual resistance curve. The results showed that the most moderate gas-to-liquid ratio and injection rate were $2: 1$ and $1 \mathrm{~mL} / \mathrm{min}$, respectively; foam performed more significant mobility control ability with the increase in permeability. After 5 days' aging, nitrogen foam still got enough mobility control ability to block water channeling. The above results demonstrate that, under high temperature and high salinity condition,
\end{abstract}

Lin Sun

williamwang1986@163.com

1 Yu Men Oil Field Company of China National Petroleum Corporation, Jiuquan, China

2 State Key Laboratory of Oil and Gas Reservoir Geology and Exploitation of Southwest Petroleum University, 305A Room of Scientific Technology Building, Xindu District, Chengdu, China

3 Northwest Oil Field Company of China Petro Chemical Corporation, Urumqi, China nitrogen foam still can act as a promising economical method for improving the mobility difference between water and oil by applying appropriate injection parameters.

Keywords Mobility control ability $\cdot$ Stability $\cdot$ Nitrogen foam $\cdot$ High temperature $\cdot$ High salinity

\section{Introduction}

Bottom water reservoir suffered from water conning/ cresting owing to formation heterogeneity, resulting in the dramatic rise of water cut, even the abandoning of well. There are plenty of chemical methods to block the uprising channel of bottom water, such as polymer, nitrogen foam and nitrogen (Pang et al. 2008, 2010; Chan 1988; Zaitoun and Pichery 2001) of which the nitrogen foam could play an important role in anti-water coning/cresting technology (AWCT) on account of its unique properties (Li et al. 2010; Schramm 1994; Simjoo and Zitha 2013; Sun et al. 2015).

Foam, considered as an impressive water profile control agent, does not directly change the water relative permeability curve or water viscosity (Bernard and Jacobs 1965; Lawson and Reisberg 1980; de Vries and Wit 1990). Foam can affect $k_{\mathrm{rw}}$ indirectly through higher trapped gas saturation and reduced water saturation (Aarra et al. 2014). Foam can greatly reduce gas mobility in porous media in two ways: reduce gas relative permeability and increase apparent gas viscosity (Falls et al. 1988). The gas relative permeability reduction effect is caused by a large effective trapped gas saturation created by foam. The dragging of flowing lamellae along pore walls leads additional resistance to the flowing of foaming bubbles compared with foam-free gas (Hirasaki and Lawson 1985). 
Zang found that foam resistance factor depends on parameters such as gas-to-liquid ratio, connate water saturation and surfactant concentration (Zang et al. 2015); however, the stability of foam was not investigated after some days' aging. Furthermore, previous research has investigated the flowing characteristic of carbon dioxide foam in some low permeable cores under over $110{ }^{\circ} \mathrm{C}$ (Mclendon et al. 2014; Steinsbø et al. 2015); however, the properties of other sorts of foam were not been covered under such experimental condition. Besides, the former investigation has barely focused on the stability of foam mobility control ability; at most the foaming solution would be tested for its foaming ability such as foaming volume and drainage half time after some days' aging under a set experimental condition.

The objective of this paper is to promote the range of nitrogen foam application under high temperature and high salinity by testing the mobility control ability. Moreover, the stability of foam mobility control ability would be observed through a kind of novel method, gaining a new sight into this characteristic of foam. This chapter proceeds with a description of experimental part, presentation and discussion of the results, and then, the main conclusions are drawn.

\section{Apparatus and procedure}

\section{Materials}

Oil sample was collected from the Northwest oil field, China. Its viscosity is $2.5 \mathrm{cP}$ at $113{ }^{\circ} \mathrm{C}$, the salinity of the formation brine is $212,813 \mathrm{mg} / \mathrm{L}$, in which the concentration of calcium and magnesium ion is over $1.28 \times 10^{4} \mathrm{mg} /$ $\mathrm{L}$, and the reservoir temperature is $113^{\circ} \mathrm{C}$, and the formation pressure is 420 bar. Unless otherwise specified, all tests were performed at $113{ }^{\circ} \mathrm{C}$, and water used was synthesized as the analysis data of the real formation water as Table 1 shows. The foam agent, which was synthesized and optimized in laboratory, was named as NS in this paper. During the whole process, the weight concentration of NS was $0.2 \%$. Nitrogen was used as the gas phase in all foam tests.

The artificial sandstone cores, which were pressed by quartz powder under suitable temperature and pressure, were applied to perform the experiments with a diameter of $2.5 \pm 0.1 \mathrm{~cm}$ and a length of $30.1 \pm 0.1 \mathrm{~cm}$. ISCO pump, produced by Teledyne Co., USA, was designed to push fluid into cores. The stainless core holder, which was fitted precisely with the cores, was conducted the whole process that consists of water injection, foam injection, the extended water injection in a heat oven (was provided by Jiangsu Haian Petroleum Apparatus Co. Ltd., China). The nitrogen flow was regulated by a gas mass flow controller supplied by Bronkhorst HighTech Co., Netherland.

\section{Experimental procedures}

On top of that, the permeability of the core in the presence of formation brine was measured; then, brine water was injected into cores to receive the basic differential pressure.

Secondly, different sorts of nitrogen foam, formed according to different experimental request, were injected into core until the differential pressure between the inlet and outlet of the core was stable. Thirdly, the two valves of the core holder were shut off, remained in the heated oven until reached the asked duration followed by the extended brine injected till the differential pressure fluctuated in a accepted scope.

Foaming solution and nitrogen were co-injected into cores, which were conducted horizontally and performed at $113{ }^{\circ} \mathrm{C}$. Both of brine water and foam were injected at a rate of $0.5 \mathrm{~mL} / \mathrm{min}$. The whole schematic of the experimental apparatus is shown in Fig. 1.

\section{Results and discussion}

\section{Mobility control ability investigation}

To quantify the mobility control ability of nitrogen foam, the resistance factor $F_{\mathrm{R}}$, which was defined as the differential pressure ratio of foam and brine injection, was often applied. Eleven series of nitrogen foam injection experiments were performed, which results are summarized in Table 2. Within these tests, the effects of gas-to-liquid ratio, injection rate and permeability on mobility control ability of nitrogen foam were investigated under experimental condition.

Table 1 Ion content of brine

\begin{tabular}{|c|c|c|c|c|c|c|c|c|}
\hline \multirow[t]{2}{*}{ Ion content } & \multicolumn{3}{|c|}{ Positive ion $(\mathrm{mg} / \mathrm{L})$} & \multicolumn{4}{|c|}{ Negative ion $(\mathrm{mg} / \mathrm{L})$} & \multirow[t]{2}{*}{ Total salinity $(\mathrm{mg} / \mathrm{L})$} \\
\hline & $\mathrm{Na}^{+}+\mathrm{K}^{+}$ & $\mathrm{Ca}^{2+}$ & $\mathrm{Mg}^{2+}$ & $\mathrm{Cl}^{-}$ & $\mathrm{Br}^{-}$ & $\mathrm{HCO}_{3}{ }^{-}$ & $\mathrm{SO}_{4}{ }^{2-}$ & \\
\hline Concentration & 68862.88 & 11517.63 & 1317.55 & 130225.6 & 180 & 115.31 & 150 & $21.2 \times 10^{4}$ \\
\hline
\end{tabular}


Fig. 1 Schematic of experimental apparatus for nitrogen foam injection, 1 nitrogen tank, 2 gas mass controller, 3 foam generator, 4 core holder, 5 back pressure valve, 6 hand booster pump, 7 atmospheric valve, 8 produced fluid metering system, 9 ISCO pump, 10 simulated water, 11 foaming solution, 12 oil, 13 heating oven

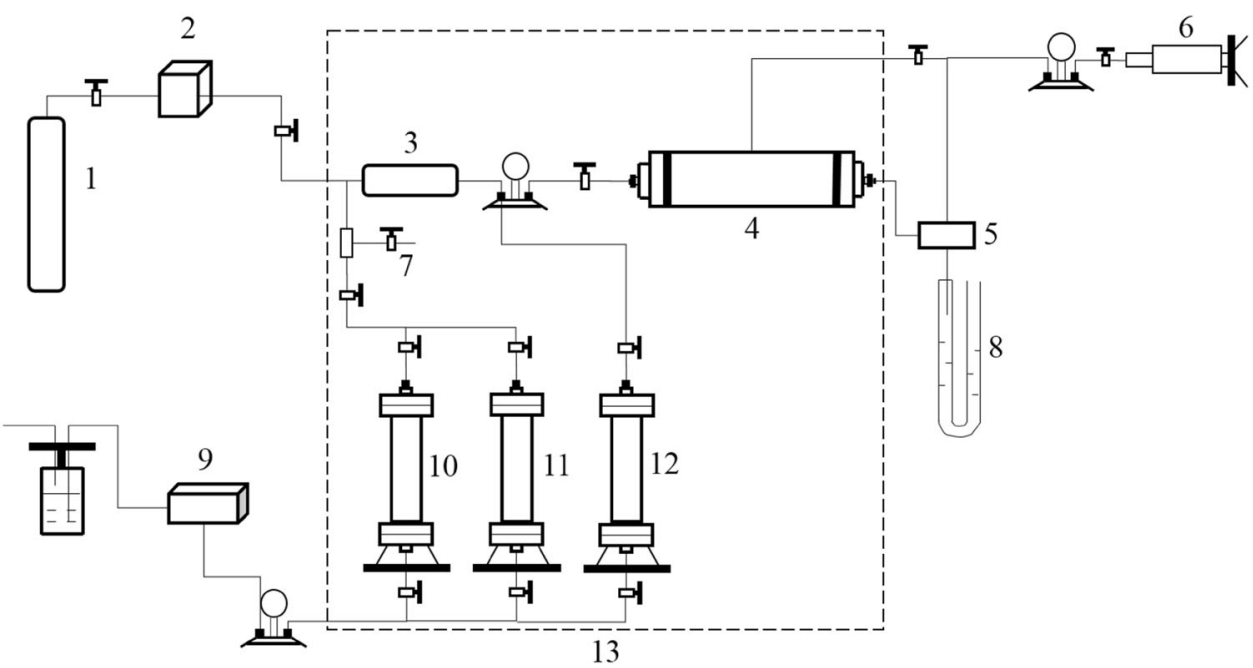

Table 2 Summary of mobility control ability of nitrogen foam tests

\begin{tabular}{llllll}
\hline Run No. & Porosity $(\%)$ & Permeability $(\mathrm{mD})$ & Gas-to-liquid ratio & Foam injection rate $(\mathrm{mL} / \mathrm{min})$ & Average resistance factor \\
\hline 1 & 24.21 & 343 & $1: 1$ & 1 & 82.46 \\
2 & 25.87 & 358 & $2: 1$ & 1 & 96.96 \\
3 & 26.83 & 324 & $3: 1$ & 1 & 52.41 \\
4 & 27.95 & 376 & $2: 1$ & 0.5 & 12.62 \\
5 & 24.15 & 332 & $2: 1$ & 1 & 91.25 \\
6 & 22.48 & 355 & $2: 1$ & 2 & 49.11 \\
7 & 17.54 & 43 & $2: 1$ & 1 & 9.9 \\
8 & 21.39 & 120 & $2: 1$ & 1 & 37.81 \\
9 & 22.32 & 364 & $2: 1$ & 1 & 101.28 \\
10 & 26.47 & 504 & $2: 1$ & 1 & 120.97 \\
11 & 29.25 & 840 & $2: 1$ & 1 & 145.28 \\
\hline
\end{tabular}

Effect of gas-to-liquid ratio on foam mobility control ability

Aiming at evaluating the gas-to-liquid ratio (GLR) on foam mobility control ability, three tests (Run 1-3) were carried out by injecting foam with different GLR. For all three runs, keeping the chemical formula constant $(0.2 \mathrm{wt} \% \mathrm{NS})$, a series of experiments were performed by increasing the GLR incrementally from 1:1-3:1. The curves of $F_{\mathrm{R}}$ versus different GLR for three foam injection tests are plotted in Fig. 2.

By checking the profile of the three curves, they differ from each other: The curve of GLR 2:1 climbs faster than the other two curves; additionally, it receives the most significant rise and in the end fluctuates around 95 which exceeds much more than that in the curves of GLR 1:1 and GLR 3:1, simultaneously, during the stabilize stage, the curve of GLR 3:1 slumps sometimes.

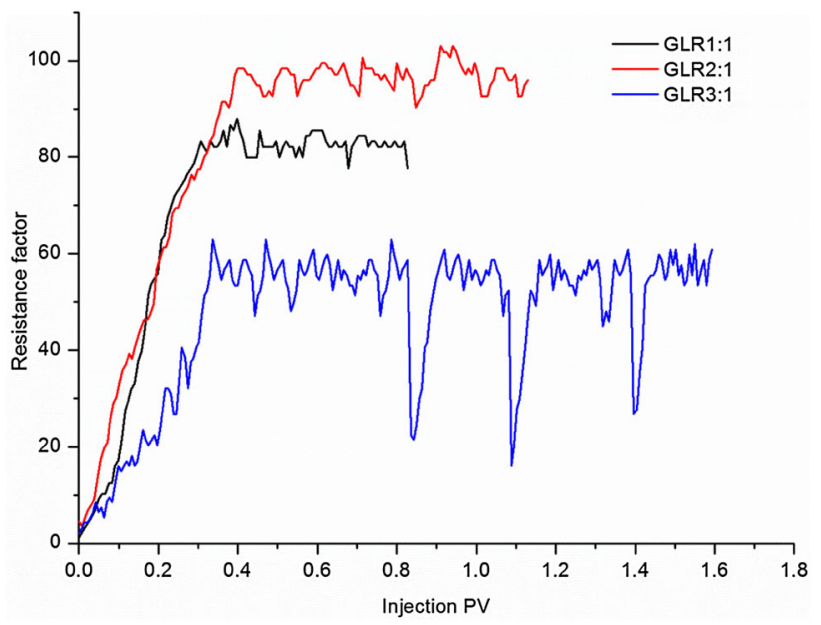

Fig. 2 Resistance factor curves of three gas-to-liquid ratio tests (run 1-run 3) 
The reason for this outcome can be explained as follows: On condition that adding the nitrogen volume moderate on the basis of stabilizing the quantity of foaming agent (from $1: 1$ to $2: 1$ ), the volume and quantity of foam would increase, triggering the improvement in foam stability and mobility control ability. Nevertheless, if more nitrogen was added (from 2:1 to 3:1), the foam would expand, causing the thinning of foam film and weakening of foam stability; what's worse, nitrogen may breakthrough and form the funnels on the $F_{\mathrm{R}}$ curve.

\section{Effect of injection rate on foam mobility control ability}

With the purpose of studying the effect of injection rate on foam mobility control ability, three series tests (runs 4-6) were designed in which injection rate ranged from $0.5,1$, $2 \mathrm{~mL} / \mathrm{min}$. Figure 3 shows the discrepancy during the injection process.

Former research achievements found that the lower the injection rate was, the higher the $F_{\mathrm{R}}$ would be. However, under experimental condition, the results represented differently: In the beginning, the curve of $0.5 \mathrm{~mL} / \mathrm{min}$ levels off for almost $0.2 \mathrm{PV}$, while the other two curves rise; then, during the stable stage, the curve of $0.5 \mathrm{~mL} / \mathrm{min}$ remains steady around 15; meanwhile, the $F_{\mathrm{R}}$ of the 1 and $2 \mathrm{~mL} /$ min was 95 and 50, respectively.

The experimental condition may account for this phenomenon: Although the high concentration can increase the boiling temperature of foam solution, the experimental temperature is too high to keep the dynamic balance on the foam film; instead, the foam solution evaporation on the film would be forced, especially under the low injection rate situation. With the increase in injection rate, the latter injected foam solution would be sheared more abundantly to produce more moderate size foam, promoting the foam

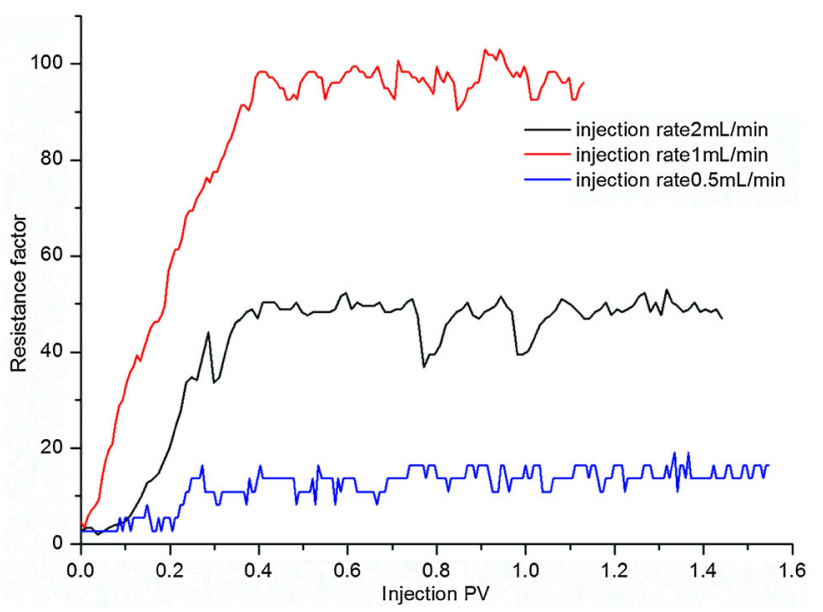

Fig. 3 Resistance factor curves of three injection rate tests (run 4 run 6) stability. By assuming that continue boosting injection rate, the shear force would be enhanced further, the decrease function of the apparent viscosity of foam would surpass the process of forming more foam, and therefore, the foam cannot build enough resistance, causing the descend of mobility control ability.

\section{Effect of permeability on foam mobility control ability}

In order to investigate the effect of core permeability on foam mobility control ability, five tests were conducted, and the core permeability was 43, 120, 348, 504, $840 \mathrm{mD}$, respectively. Figure 4 shows the resistance factor curves of five permeabilities.

What is shown in the graph is that: In the whole process of foam injection, five curves of resistance factor are rise, and the climbing slope and velocity of the curves are differed from each other yet. The higher permeability core obtains more resistance factor, and it also augments faster. The specific results are shown in Table 3.

The wider pore throat can shed light on the diversity: The higher the permeability is, the wider the average size of pore throat would be; in this throat, foam would be shear more gently than that in the narrower throat, triggering higher apparent viscosity of foam, which is crucial to build more flowing resistance; consequently, nitrogen foam can acquire the most remarkable mobility control ability in the $840 \mathrm{mD}$ core.

\section{Stability of mobility control ability}

The residual resistance factor $F_{\mathrm{RR}}$, which was defined as the pressure drop ratio of the two brine injection stages after and before foam injection, was utilized to measure the stability of foam mobility control ability. Two series tests

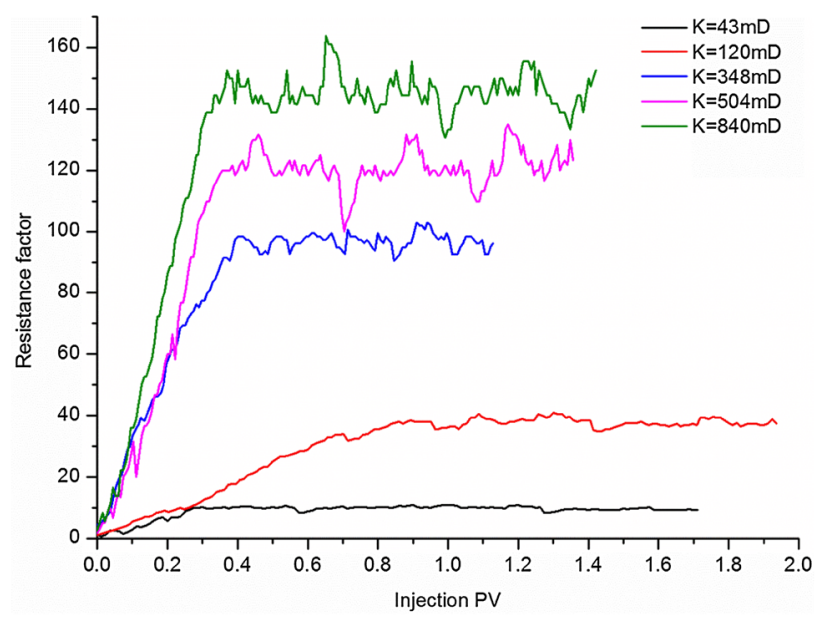

Fig. 4 Resistance factor curves of five permeability tests (run 7-run 11) 
Table 3 Summary of stability of mobility control ability of nitrogen foam tests

\begin{tabular}{llllllll}
\hline $\begin{array}{l}\text { Run } \\
\text { No. }\end{array}$ & $\begin{array}{l}\text { Aging } \\
\text { duration } \\
\text { (days) }\end{array}$ & $\begin{array}{l}\text { Porosity } \\
(\%)\end{array}$ & $\begin{array}{l}\text { Permeability } \\
(\mathrm{mD})\end{array}$ & $\begin{array}{l}\text { Initial oil } \\
\text { saturation }(\%)\end{array}$ & $\begin{array}{l}\text { Oil saturation when } \\
\text { injecting foam }(\%)\end{array}$ & $\begin{array}{l}\text { Resistance when ceasing } \\
\text { foam injection }\end{array}$ & $\begin{array}{l}\text { Average residual } \\
\text { resistance factor }\end{array}$ \\
\hline 12 & 0 & 24.13 & 366 & 76.12 & 43 & 3.82 & 2.05 \\
13 & 5 & 22.38 & 348 & 72.38 & 41.96 & 2.93 & 1.2 \\
\hline
\end{tabular}

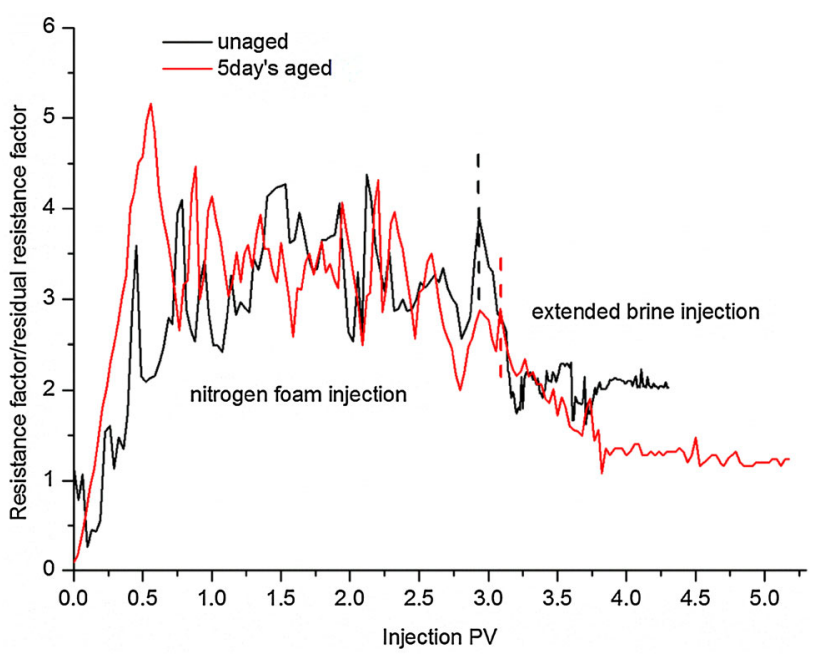

Fig. 5 Resistance factor and residual resistance factor curves of two aging duration tests (run 12-run 13)

were carried out to study the effect of oil on stability of foam mobility control ability by comparing the $F_{\mathrm{RR}}$ alteration of aging 5 days and unaged foam. The properties of the cores and results of every stage are summarized in Table 3. An extensive de-emulsification process was required when the produced effluent was oil-in-water emulsion. Figure 5 demonstrates the $F_{\mathrm{RR}}$ changes of nitrogen foam between unaged and aging 5 days in the $113{ }^{\circ} \mathrm{C}$ oven.

Figure 5 compares the difference of the two processes: The stability of foam would be affected dramatically at the presence of oil, and the stable $F_{\mathrm{R}}$ numerical value of the two curves was much smaller than that under non-oil condition. Simultaneously, after 5 days' aging, the $F_{\mathrm{RR}}$ collapsed apparently in contrast to the unaged foam.

One reason might can be cited to justify this: On account of the defoaming function of oil, the foam would be prone to break in the oil bank; beyond that, once foam had been contacted with oil, the re-foaming ability, which was one of its properties, would descend, resulting in the decline of the quantity of reproducing foam; taking all the above into consideration, on the profile of curve, the $F_{\mathrm{R}}$ of foam in the presence of oil was much smaller. Additionally, after 5 days' aging under $113{ }^{\circ} \mathrm{C}$ condition, although the curve fluctuated, which indicated that foam was produced in the cores, the foaming solution and nitrogen cannot produce enough foam to build ample resistance by virtue of the activity loss of foaming solution molecule, causing the $F_{\mathrm{RR}}$ slump of the aged foam.

To illuminate this nature in particular, foam was in accordance with the demand of anti-water coning/cresting, which required the flowing resistance to reduce in the oil bank channel; instead, the flowing resistance in the channel with low oil saturation would much higher than that in oil bank channel, which would be convenient for the sweep area promotion in the oil bank channel by bottom water.

\section{Conclusion}

The mobility control ability of nitrogen foam which was generated by $0.2 \mathrm{wt} \%$ NS was studied under different gasto-liquid ratio by measuring the resistance factor $F_{\mathrm{R}}$, foam injection rate and permeability, the stability of mobility control ability through some days' aging as well. The whole experimental process was proceeded at a back pressure of $420 \mathrm{bar}$ and the ambient temperature was $113{ }^{\circ} \mathrm{C}$, and the formation brine salinity was $21.2 \times 10^{4}$ $\mathrm{mg} / \mathrm{L}$. The main conclusions from this study are as follows:

1. By increasing gas-to-liquid ratio from $1: 1$ to $2: 1, F_{\mathrm{R}}$ was promoted dramatically; but on proceeding up to 3:1, the $F_{\mathrm{R}}$ curve descended and fluctuated, indicating that the most suitable gas-to-liquid ratio was 2:1 under this experimental condition.

2. Compared with former investigation accomplishments, what is different was that too slow injection rate $(0.5 \mathrm{~mL} / \mathrm{min})$ would boost the evaporation speed, resulting in the weaker mobility control ability under experimental condition. The moderate injection rate $(1 \mathrm{~mL} / \mathrm{min})$ would receive more outstanding $F_{\mathrm{R}}$ than that under the rate of $2 \mathrm{~mL} / \mathrm{min}$.

3. The higher the permeability of cores was (from $43 \mathrm{mD}$ to $840 \mathrm{mD}$ ), the higher the $F_{\mathrm{R}}$ was, which was in accordance with the former study on the effect of diameter of pore on the mobility control ability of foam.

4. With a novel insight into the stability of mobility control ability of foam, after 5 days' aging, the 
nitrogen foam still got some ability to control the water channeling, which was suitable for demand of antiwater coning for bottom water reservoir.

Acknowledgement The authors grateful acknowledge the financial and material support from Northwest oil field of SINOPEC and the special fund of China's central government for the development of local colleges and universities-the project of national first-level discipline in Oil and Gas Engineering.

Open Access This article is distributed under the terms of the Creative Commons Attribution 4.0 International License (http:// creativecommons.org/licenses/by/4.0/), which permits unrestricted use, distribution, and reproduction in any medium, provided you give appropriate credit to the original author(s) and the source, provide a link to the Creative Commons license, and indicate if changes were made.

\section{References}

Aarra MG, Skauge A, Solbakken J, Ormehaug PA (2014) Properties of $\mathrm{N}_{2}$ and $\mathrm{CO}_{2}$ foams as a function of pressure. SPE Reg 116(4):72-80

Bernard G, Jacobs WL (1965) Effect of foam on trapped gas saturation and on permeability of porous media to water. SPE J 5(4):295-300

Chan KS (1988) Water coning treatments using a non-polymer gelling system. Am Chem Soc Div Pet Chem Prep 33:1 (United States)

de Vries AS, Wit K (1990) Rheology of gas/water foam in the quality range relevant to steam foam. SPE J 5(2):185-192

Falls AH, Hirasaki GJ, Patzek TW et al (1988) Development of a mechanistic foam simulator: the population balance and generation by snap-off. SPE Res Eng 3(3):884-892

Hirasaki GJ, Lawson JB (1985) Mechanisms of foam flow in porous media: apparent viscosity in smooth capillaries. SPE J 25(2):176-190
Lawson JB, Reisberg J (1980) Alternate slugs of gas and dilute surfactant for mobility control during chemical flooding. Present at the SPE/DOE enhanced oil recovery symposium, Tulsa, Oklahoma, USA, 20-23 April

Li RF, Yan W, Liu S, Hirasaki G, Miller C (2010) Foam mobility control for surfactant enhanced oil recovery. Spe J 15(4):928-942

Mclendon WJ, Koronaios P, Enick RM, Biesmans G, Salazar L, Miller A et al (2014) Assessment of $\mathrm{CO}_{2}$ soluble non-ionic surfactants for mobility reduction using mobility measurements and CT imaging. J Pet Sci Eng 119(3):196-209

Pang ZX, Cheng LS, Jia Feng XU, Feng RY (2008) Application of material balance method to nitrogen anti-water-coning technology. Pet Explor Dev 35(2):234-238

Pang ZX, Liu HQ, Liu XL (2010) Experiments on blocking ability of nitrogen foam and its application in anti-water-coning. Pet Sci Technol 28(12):1260-1276

Schramm LL (1994) Foam sensitivity to crude oil in porous media in foams, fundamentals and applications in the petroleum industry. In: Schramm LL (ed) Advances in chemistry, vol 242. American Chemical Society, Washington DC, pp 165-197

Simjoo M, Zitha PL (2013) Effects of oil on foam generation and propagation in porous media. In: SPE enhanced oil recovery conference, Society of Petroleum Engineers

Steinsbø M, Brattekås B, Ersland G, B $\varnothing$ K, Opdal I, Tunli R, et al. (2015) Foam as mobility control for integrated $\mathrm{CO}_{2}$ EOR in fractured carbonates. IOR 2015 18th European symposium on improved oil recovery

Sun L, Wang B, Pu W, Yang H, Shi M (2015) The effect of foam stability on foam flooding recovery. Pet Sci Technol 33(1):15-22

Zaitoun A, Pichery T (2001) A successful polymer treatment for water coning abatement in gas storage reservoir. SPE annual technical conference and exhibition, 30 Sept-3 Oct, New Orleans, Louisiana

Zang J, Li X, Chen Z et al. (2015) An analytical model of foam resistance factor in gas foam flooding. Present at the Nigeria annual international conference and exhibition held in Lagos, Nigeria, 4-6 Aug 2015 